\title{
The effect of different suctioning modalities on physiologic measures and the incidence of ventilator associated pneumonia
}

\author{
Khaled Ibrahim Hussein ${ }^{1}$, Eman Zahran ${ }^{2}$, Lina Kurdahi Badr ${ }^{* 3}$, Zeina Kanafani ${ }^{1}$ \\ ${ }^{1}$ American University Medical Center, Beirut, Lebanon \\ ${ }^{2}$ Emergency and critical care nursing, faculty of health sciences, Beirut Arab university, Beirut, Lebanon \\ ${ }^{3}$ Azusa Pacific University, Azusa, California, United States
}

Received: January 19, 2016

Accepted: June 21, 2016

Online Published: August 17, 2016

DOI: $10.5430 /$ jnep.v7n1p1

URL: http://dx.doi.org/10.5430/jnep.v7n1p1

\begin{abstract}
Objective: To compare physiologic measures and the incidence of ventilator associated pneumonia (VAP) using different modalities of endotrachael tube (ETT) suctioning.

Methods: A Quasi-experimental design was used with 80 adults in an intensive care unit. Two modalities of suctioning were compared: 1) not instilling normal saline (NS) into the ETT before suctioning, and 2) instilling NS into the ETT tube before suctioning. The outcome variables were: physiologic measures (heart rate, respiratory rate and blood pressure and oxygen saturation), the incidence of Ventilator Associated Condition (VAC) and Possible Ventilator Associated Pneumonia (PVAP) at day 5 after mechanical ventilation.

Results: There were no differences in the physiologic measures assessed at day 5 and a significantly higher rate of VAC in patients who had NS installed $(p=.009)$. Four patients developed PVAP compared to 10 patients in group 2 where NS was installed but that did to reach significance $(p=.077)$. Factors associated with VAC were age, WBC $>12,000$, antibiotic use, amount of secretions, and NS installation. The same factors were associated with the development of PVAP with the exception of NS installation which did not reach significance.

Conclusions: Installing NS in the ETT tube did not result in significant physiologic changes at day 5, and more rates of VAC and PVAP were noted. Therefore, the use of this procedure is questionable and further studies are needed to provide conclusive evidence.
\end{abstract}

Key Words: Normal saline installation, Endotracheal suctioning, Intensive care, Ventilator associated pneumonia

\section{INTRODUCTION}

One of the most common and serious infections in intensive care units is ventilator-associated pneumonia (VAP) which is considered is a healthcare associated infection (HAI). $10 \%$ to $30 \%$ of patients receiving mechanical ventilation in the intensive care unit (ICU) develop VAP and between $24 \%$ and $76 \%$ of patients with VAP die. ${ }^{[1]}$ In addition, patients who develop VAP have increased length of hospital stay, and increased healthcare costs. ${ }^{[2-4]}$ Patients who are elderly, males and those who have other comorbidities such as chronic obstructive lung disease or diabetes are at much higher risk to develop VAP.

Ventilator-associated pneumonia is defined as a subtype of pneumonia that occurs up to 48 hours after initiation of meStates.

*Correspondence: Lina Kurdahi Badr; Email: lbadr@apu.edu; Address: Azusa Pacific University, 701 E Foothill Blv. Azusa, California, United 
chanical ventilation in patients who had no preexisting lung infection at the time of intubation and the ventilator was in place on the date of event or the day before. ${ }^{[5]}$

Although there has been a steady decline in reported VAP rates over the last several years in the USA, with rates ranging from 0.0 to 5.8 per 1,000 ventilator days in various hospitals, globally the prevalence is $15.5 \%$ with even higher rates in developing counties reaching up to 19.4 cases per 1,000 ventilator-days. ${ }^{[6-8]}$ Therefore, the prevention of VAP is desirable to improve patient's outcomes and is a marker of quality of patient care. ${ }^{[2,3,9]}$

The majority of patients in ICUs require mechanical ventilation (MV) via an artificial airway which compromises the mucociliary escalator, increases the volume and tenacity of mucus, and suppresses the cough reflex, predisposing them to infections. ${ }^{[3,4]}$ Airway management of patients on mechanical ventilation represents the cornerstone of nursing care for critically ill patients. To maintain a patent airway and to manage secretions, the most widespread practice nurses throughout the world use is to lubricate the catheter with Normal Saline (NS) and then to install NS directly into the trachea via an artificial airway or an endotracheal tube (ETT). ${ }^{[10]}$ Installing NS into the ETT is believed to soften the thick secretions, and facilitate the removal of secretions. ${ }^{[9,11]}$ Despite the popularity of such a practice, many of practitioners believe that it may be harmful to patients. ${ }^{[10-12]}$

The potentially harmful effects of NS Installation are counterbalanced by positive effects. The negative effects of NS instil- lation include decreased oxygenation, dyspnea, an increase in the incidence of lower respiratory tract contamination, dislodgement of bacterial colonies, anxiety and pain. ${ }^{[13,14]}$ The positive effects of NS installation include: an increase in the amount of secretions removed, stimulation of coughing, and decreased rates of VAP. ${ }^{[11,15]}$ Considering the pros and cons of NS installation, the clinical practice guidelines published by the American Association for Respiratory Care in 2010, suggest that the routine use of NS instillation should not be performed. Despite these recommendations, organizational change toward best suctioning practices has not been without challenges. Several institutions still have policies that recommend instilling normal saline for thick secretions and many respiratory therapists as nurses continue to use NS for suctioning. ${ }^{[16-18]}$

Considering these controversies and the new CDC guidelines (2015) for diagnosing VAP, the current study was conducted. The diagnosis of VAP is challenging and opinions are divided on the optimal method for diagnoses with considerable inter-observer variability. ${ }^{[13,19]}$ A combination of clinical, radiographic, and microbiological criteria are often used for diagnosis but, the accurate diagnosis and treatment of VAP remains controversial. The 2015, CDC criteria, ${ }^{[5]}$ used to diagnose Ventilator Associated Events (VAE) include three tiers within the VAE algorithm: 1) Ventilator-Associated Condition (VAC); 2) Infection-related Ventilator Associated Complication (IVAC); and 3) Possible VAP (PVAP). For this study we focused on VAC and on possible onset PVAP as noted in Table 1.

Table 1. Surveillance for Ventilator Associated Events (VAE)

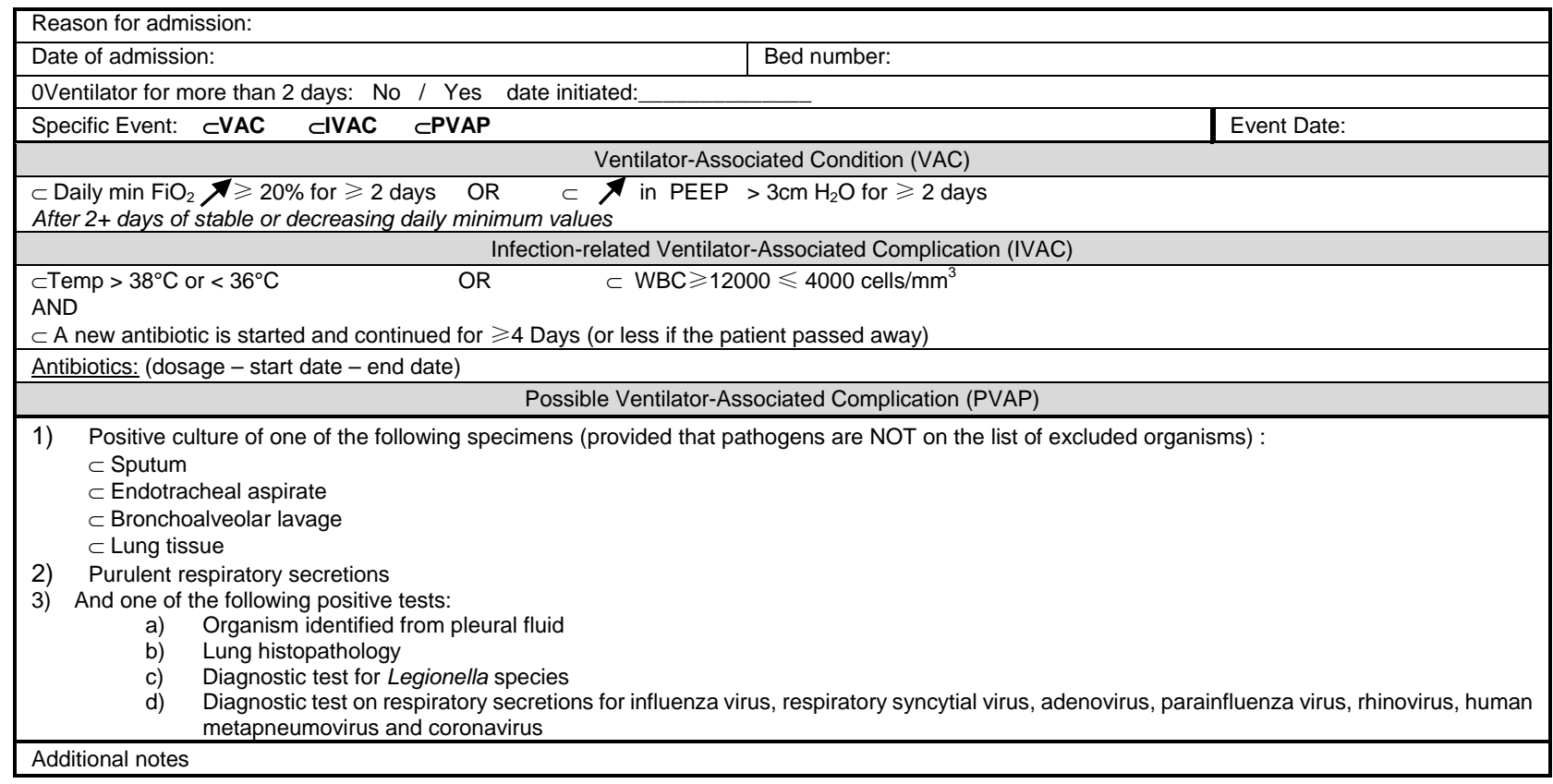


Based on the important role critical care nurses play in VAP prevention, and the lack of consensus on best practice guidelines, the purpose of the study was to provide further evidence to the effect of different suctioning modalities on mean physiologic parameters arterial oxygen saturation $\left(\mathrm{SaO}_{2}\right)$ heart rate (HR), respiratory rate (RR) and mean blood pressure (BP) as primary outcomes and on the incidence of VAC and PVAP as a secondary outcomes at 5 day on Mechanical Ventilation (MV) based on the new 2015 CDC criteria. The rationale for assessing mean physiologic measures on day 5 was based on the fact that earlier studies have been consistent in reporting that installing normal saline (NS) will decrease oxygenation, and increase HR and RR immediately after suctioning. ${ }^{[11,18]}$ We were more interested if such changes are sustained over time. The following 2 hypotheses and 2 research questions were tested:

Hypothesis 1: Installing NS into the ETT during suctioning results in decreased mean $\mathrm{SaO}_{2}$, and an increase mean HR $\mathrm{RR}$ and $\mathrm{BP}$ at day 5 compared to not installing NS.

Hypotheses 2: Installing NS into the ETT during suctioning results in more rates of VAC and PVAP at day 5 compared to not installing NS.

Research question 1: What are the factors associated with VAC and PVAP?

Research question 2: What are the most common organisms isolated?

\section{MATERIALS AND METHODS}

\subsection{Design}

A quasi experimental single unit research design was used in order to decrease the contamination of the intervention by nurses between groups.

\subsection{Setting}

This study was conducted at an intensive care unit of hospital in Lebanon in 2014-2015.

\subsection{Subjects}

A convenient sample of 80 newly admitted, mechanically ventilated patients of both genders between the ages of 18-80 years were selected. All patients were recruited when they had been intubated by an ETT for 2 days, were on continuous monitoring and had arterial lines to measure blood gasses. Patients were excluded if they were previously infected with pneumonia, and whose Deep Tracheal Aspiration (DTA) cultures were already positive and who were hemodynamically unstable. The inclusion and exclusion criteria for patient selection was based on previous similar studies. ${ }^{[20,21]}$

Patients were allocated sequentially to one of two methods Published by Sciedu Press of suctioning with 40 patients in each group. In the first 3 months of the study, the control group was enrolled and in the next 3 months the intervention group was enrolled to avoid contamination of the intervention. Sample size calculation was based on a significant reduction of $\mathrm{SaO}_{2}$ between groups based in a previous study, ${ }^{[22]}$ with power of $80 \%$ and an alpha of 0.05 .

\subsection{Materials}

Based on previous studies, ${ }^{[7,19,23]}$ that have documented the factors that could interfere with the incidence of VAP, the following variables were recorded, age, gender, diagnosis, characteristics of sputum (amount in ccs and color) and antibiotics administered. Physiological parameters were recorded every 3 hours for 5 days and included: HR, RR, $\mathrm{BP}$, while arterial oxygen saturation $\left(\mathrm{SaO}_{2}\right), \mathrm{FiO}_{2}$ and PEEP were recorded electronically every hour and the daily minimum $\mathrm{FiO}_{2}$ and PEEP that are maintained for at least one hour were recorded for 5 days. The diagnosis of VAC and early onset (less than 5 days) PVAP was based on the 2015 $\mathrm{CDC}^{[5]}$ criteria as noted on the data gathering sheet in Figure 1 . All diagnoses were made by the attending physician and the infection control medical team. All the radiographs reports were assessed and diagnosed by both the attending physician and a radiologist blinded to study groups. In addition to diagnosing VAC and PVAP, cultures were obtained on deep tracheal aspirate (DTA) by a respiratory therapist under aseptic technique on day 5 to identify the isolated microorganisms. Susceptibility patterns were determined by the disk-diffusion method according to the guidelines of the National Committee for Clinical Laboratory Standards. ${ }^{[24]}$

Ethical approval to conduct the study was obtained from Beirut Arab University and the Lebanese Hospital and all patients or their significant other signed a consent form.

\subsection{Procedure}

Eligible patients were approached and explained the purpose of the study (if conscious) or a family member if unconscious) and informed consent for participation was obtained from the patient if conscious or a designated family member if not conscious. Patients remained in the study for five days or until being extubated (not less than 3 days and not more than 5 days). The attending physicians were blinded to the study group. The Principal investigator instructed the nurses on the unit about the study and the importance of following the protocol in terms on using NS or not using NS on the patents allocated to each group. Attending physicians were available 24 hours a day to treat any patient who deteriorated during the study. Patients in both groups were suctioned using the closed suctioning system when needed and accord- 
ing to hospital policy and standard guidelines. ${ }^{[16,25]}$ These included:

- Hyperoxygenation with $100 \%$ oxygen before suctioning for 30-60 seconds and determined according to the following indicators.

- Presence of hypoxemia including early and late signs. Early signs of hypoxemia include: restlessness, tachypnea, tachycardia, and decreased $\mathrm{SaO}_{2}$ levels. Late signs include: cyanosis, disturbed level of consciousness, cardiac dysrhythmias.

- Adventitious breath sounds such as rales, visualization of secretions, and absence of spontaneous cough,

- Increased peak inspiratory pressure during volume controlled mechanical ventilation or decreased tidal volume during pressure controlled ventilation.

Group one was subjected to the irrigation of the catheter with NS before and after suctioning, without NS instillation into the ET tube.

Group two was subjected to the irrigation of the catheter with NS before and after suctioning, with 6-8 cc of NS instillation into the ETT.

The first group was enrolled in the first 3 months of the study and group 2 was enrolled in the next 3 months of the study. This group allocation was done in order to decrease the contamination of the intervention by nurses between groups.

\subsection{Data analysis}

Data were analyzed using SPSS software package version 22.0 (SPSS, Chicago, IL, USA). The VAP rate per 1,000 ventilator days was calculated by dividing the number of VAPs by the number of ventilator days and multiplying the result by 1,000. Continuous variables were expressed as means, and standard deviations (SD), while categorical variables were expressed as frequencies and percentages. Differences between patient characteristics and physiologic measures at baseline were compared between groups using $t$-tests for continuous variables and Chi Square or Fisher's exact test for categorical variables. The mean for the 5 day physiologic measures; HR, RR, BP and $\mathrm{SaO}_{2}$ were calculated then analysis of variance (ANOVA) was used to assess any differences between groups. Odds Ratios (ORs) were used to compare the rates of VAC ad PVAP in the two groups. Bivariate analysis using Chi square and Odds Ratio (OR) were used to assess the variables associated with VAC and PVAP (age was categorized into 3 groups $21-40,41-60$ and 61-80 to facilitate interpretation of the data). Two logistic regression models were conducted one for VAC and one for PVAP to assess which factors remained significant. The $p$ value was assumed to be significant at 05 .

4

\section{RESULTS}

Table 2 shows a comparison of the participant characteristics in the two study groups. Thirty nine patients (48.7\%) were males, while 41 patients $(51.3 \%)$ were females, the mean age was $62.9 \pm 20.11$ years. The majority of participants had respiratory diseases $(50.5 \%)$, followed by neurological diseases $(27.5 \%)$, and cardiac diseases (15\%). On admission to the ICU about one third (33.7\%) were on broad spectrum antibiotics and the rest of the sample did not receive antibiotics $(66.2 \%)$. The WBC count was $1,362.33 \pm 4,632.52$ in group 1 and 14,468.97 $\pm 7,806.66$ for group 2 . With regards to the physiologic variables, the mean values for HR were $84.19 \pm 12.66$ in group 1 , and $78.93 \pm 26.46$ beats/minute in group 2. The mean values of arterial BP were $93.33 \pm$ $17.34 \mathrm{mmHg}$ for group 1 and $89.54 \pm 19.16$ for group 2. For RRs the mean $19.37 \pm 5.42$ for group 1 and $20.66 \pm 4.88$ for group 2 cycles/minute. The mean value for temperature was; $36.36 \pm 1.64^{\circ} \mathrm{C}$ for group 1 and $36.49 \pm 2.06^{\circ} \mathrm{C}$ for group 2. The only difference between groups was in the amount of secretions which were more excessive in group 2 compared to group $1, \chi^{2}=6.69, p=.036$. Chi square and $t$-tests showed no other statistically significant difference among the other variables between groups in relation to their characteristics and physiologic variables.

\section{Hypotheses 1: Effect of suctioning technique on physio- logic measures}

There were no differences between groups on all four physiologic measures at day 5 (see Table 3 ). Heart rate was higher in group 2 that had the NS installed but that did not reach significance.

\section{Hypotheses 2 \& 3: Effect of suctioning technique on rates of VAC and PVAP}

In group 1, which did not have NS installed, 8 patients developed a VAC while group 2, had 19 patients develop VAC, $\chi^{2}$ $=6.76, p=.009$, the odds for not having a VAC was 0.27 (CI $=0.10-0.74)$. In terms of PVAP, 4 patients developed PVAP compared to 10 cases in group 2 where NS was installed however, the difference was not significance, $\chi^{2}=3.12, p=$ .077 , the OR for not having PVAP was $0.43(\mathrm{CI}=0.10-1.17)$.

\section{Research question 1: What are the factors associated with VAC and PVAP?}

The factors that were associated with developing PVAP were age, $\chi^{2}=20.25, p=.001, \mathrm{WBC}>12,000, \chi^{2}=39.19, p$ $=.000$, antibiotic use, $\chi^{2}=19.06, p=.001$, and amount of secretions, $\chi^{2}=17.06, p=.004$ (see Table 4). The same variables were predictive of VAC with the exception of NS instillation which was significant at $\mathrm{OR}=1.45, \mathrm{CI}=1.23$ $3.44, p=.03$. only difference for developing VAC was suc- 
tioning which was significant at $\chi^{2}=13.22, p=.05$. We performed 2 logistic regression analysis with the latter significant variables along with suctioning method. The variables that remained significantly predictive of PVAP were: age, $\mathrm{OR}=1.96, \mathrm{CI}=1.2-2.14, p=.04$, antibiotic use, $\mathrm{OR}=0.47$, $\mathrm{CI}=0.007-0.76, p=.01, \mathrm{WBC}>12,000, \mathrm{OR}=1.48 . \mathrm{CI}$ $1.76-5.35, p=.05$. However, NS instillation did not reach significance, $\mathrm{OR}=1.23, \mathrm{CI}=0.95-1.34$ (see Table 5 for PVAP). The same variables were also predictive of VOC.

\section{Research question 2: What are the most common organ- isms isolated?}

Table 6 shows the distribution of the isolated microorganisms in the 37 patients in the two groups. Group 1 had 15 organisms isolated compared to group 2 that had 28 organisms isolated (6 patients had 2 organisms isolated). The most frequent isolated microorganism was Candida in 13 patients (30.2\%), followed by E-coli in 9 patients (20.9\%) and Pseudomonas in 8 patients (18.6\%). No microorganisms were isolated in 46 participants (57.5\%). Fisher's exact test showed that there was no statistically significant difference among the study groups in respect to the deep tracheal aspirate cultures.

\section{Discussion}

Mechanically ventilated patients require tracheal suctioning as they have impaired airway protective mechanisms. Tracheal suctioning is a frequent and an integral part of airway management in ICUs. It is one of the most common procedures performed by nurses for mechanically ventilated, however, it is associated with the risk of developing infection and VAP. This study focused at comparing the effect of different suctioning modalities on physiologic measures and the incidence of VAC and PVAP.

Table 2. Participants' characteristics by study group

\begin{tabular}{|c|c|c|}
\hline & No Installation & Yes Installation \\
\hline & Mean \pm Standard deviation & Mean \pm Standard deviation \\
\hline Age & $59.1 \pm 18.38$ & $63.53 \pm 19.59$ \\
\hline HR & $84.19 \pm 12.66$ & $78.93 \pm 20.46$ \\
\hline Mean BP & $93.33 \pm 17.34$ & $89.54 \pm 19.16$ \\
\hline $\mathrm{SaO}_{2}$ & $93.5 \pm 4.55$ & $94.6 \pm 6.19$ \\
\hline RR & $19.37 \pm 5.42$ & $20.66 \pm 4.88$ \\
\hline Temp & $36.37 \pm 1.65$ & $36.49 \pm 3.06$ \\
\hline $\mathrm{F}_{10}$ & $44.73 \pm 11.69$ & $51.27 \pm 15.23$ \\
\hline \multirow[t]{2}{*}{ WBC } & $13623.33 \pm 4632.52$ & $14468.97 \pm 7806.66$ \\
\hline & Number Percent & Number Percent \\
\hline \multicolumn{3}{|l|}{ Gender } \\
\hline Male & $18(45)$ & $21(52.5)$ \\
\hline Female & $22(55)$ & $19(47.5)$ \\
\hline \multicolumn{3}{|c|}{ Characteristics of Sputum } \\
\hline \multicolumn{3}{|l|}{ Color } \\
\hline White & $29(72.5)$ & $26(65.0)$ \\
\hline Yellow & $11(27.5)$ & $14(35.0)$ \\
\hline \multicolumn{3}{|l|}{ Amount } \\
\hline Mild 0-5 cc & $26(65.0)$ & $16(40.0)$ \\
\hline Moderate 5-10 cc & $9(22.5)$ & $10(25.0)$ \\
\hline Excessive 10-15 cc & $5(12.5)$ & $14(35.0)^{*}$ \\
\hline \multicolumn{3}{|l|}{ Bloody } \\
\hline Yes & $5(12.5)$ & $8(20.0)$ \\
\hline No & $35(87.5)$ & $32(80.0)$ \\
\hline \multicolumn{3}{|l|}{ Antibiotics } \\
\hline Yes & $12(30)$ & $15(37.5)$ \\
\hline No & $28(70)$ & $25(62.5)$ \\
\hline \multicolumn{3}{|l|}{ Diagnosis } \\
\hline Respiratory & $21(52.5)$ & $19(47.5)$ \\
\hline Neurology & $12(30.0)$ & $10(25.0)$ \\
\hline Cardiac & $5(12.5)$ & 7 (17.5) \\
\hline Other & $2(5.0)$ & $4(10.0)$ \\
\hline
\end{tabular}


Table 3. Effect of Suctioning method on Physiologic variables at day 5

\begin{tabular}{llll}
\hline Variable & Mean \pm SD & F value & p \\
\hline SaO day 5 & & & .68 \\
$\quad$ NS not installed & $94.24 \pm 17.41$ & 0.17 & \\
NS Installed & $92.36 \pm 20.99$ & & .36 \\
Respiratory rate & & 0.83 & .07 \\
NS not installed & $19.06 \pm 4.23$ & & \\
NS Installed & $21.11 \pm 8.13$ & & \\
HR & & 3.32 & .59 \\
NS not installed & $78.64 \pm 12.74$ & & \\
NS Installed & $83.44 \pm 10.71$ & & \\
Mean BP & & 0.28 & \\
NS not installed & $33.96 \pm 45.39$ & & \\
NS Installed & $29.63 \pm 44.25$ & & \\
\hline
\end{tabular}

Table 4. Variables associated with PVAP $(\mathrm{N}=80)$

\begin{tabular}{|c|c|c|c|}
\hline Variable & $\begin{array}{l}\mathrm{N}=14 \text { PVAP } \\
\text { positive }\end{array}$ & $\begin{array}{l}\mathrm{N}=66 \text { PVAP } \\
\text { negative }\end{array}$ & $p$ \\
\hline \multicolumn{4}{|l|}{ Age } \\
\hline $21-40$ & 0 & 29 & \multirow{3}{*}{.001} \\
\hline $41-60$ & 3 & 24 & \\
\hline $61-80$ & 11 & 13 & \\
\hline \multicolumn{4}{|l|}{ Gender } \\
\hline Male & 9 & 28 & \multirow[t]{2}{*}{.132} \\
\hline Female & 5 & 38 & \\
\hline \multicolumn{4}{|l|}{ WBC } \\
\hline$>12,000$ & 12 & 4 & \multirow[t]{2}{*}{.000} \\
\hline$<12,000$ & 2 & 62 & \\
\hline \multicolumn{4}{|l|}{ Antibiotic use } \\
\hline Yes & 3 & 53 & \multirow[t]{2}{*}{.000} \\
\hline No & 11 & 13 & \\
\hline \multicolumn{4}{|c|}{ Characteristics of Sputum } \\
\hline \multicolumn{4}{|c|}{ Amount } \\
\hline Mild $0-5 \mathrm{cc}$ & 1 & 36 & \multirow{3}{*}{.004} \\
\hline Moderate $5-10 \mathrm{cc}$ & 3 & 18 & \\
\hline Excessive $10-15 \mathrm{cc}$ & 10 & 12 & \\
\hline \multicolumn{4}{|l|}{ Bloody } \\
\hline Yes & 8 & 50 & \multirow[t]{2}{*}{.275} \\
\hline No & 6 & 16 & \\
\hline \multicolumn{4}{|l|}{ Color } \\
\hline White & 4 & 36 & \multirow[t]{2}{*}{.077} \\
\hline Yellow & 10 & 30 & \\
\hline \multicolumn{4}{|l|}{ Diagnosis } \\
\hline Respiratory & 10 & 30 & \multirow{4}{*}{.345} \\
\hline Neurologic & 2 & 20 & \\
\hline Cardiac & 1 & 11 & \\
\hline Other & 1 & 5 & \\
\hline
\end{tabular}

The results show that there was no statistically significant difference among the study groups in relation to their characteristics, antibiotic intake, $\mathrm{FiO}_{2}$ requirements, sputum culture and characteristics (except for amount of sputum) at baseline or at the time of enrollment which was after 2 days on MV. This indicates that any difference in the results among the study groups is related to the technique of suctioning and not to any differences in patients' characteristics.

The mean age group for the participants was 62.5 years with the majority between 61 and 80 years $(46.2 \%)$. This is similar to what has been mentioned in earlier studies in ICUs as aging is characterized by the progressive loss of organ system function, impaired adaptive and homeostatic mechanisms, and the activation of the entire inflammatory cascade which lead to increased susceptibility of morbidities and mortality. ${ }^{[1,22,26]}$ The diagnostic distribution of our sample is also similar to previous studies. ${ }^{[14,25]}$ This is explained by the fact that patients with respiratory disorders are the ones that are most likely to require mechanical ventilation.

There was no effect of suctioning on mean physiologic measures on day 5 . While most earlier studies ${ }^{[3,8,22,25]}$ focused on changes in $\mathrm{SpO}_{2}$ or $\mathrm{SaO}_{2}$, HR, BP and RR, immediately after suctioning, we were more interested in assessing whether these changes were sustainable at day 5 which is clinically more relevant. Previous studies indicate that RR, HR $\mathrm{BP}$ increase immediately post suctioning and return to the baseline after 5 minutes which is due to the fact that suctioning stimulates the sympathhetic nervous system. ${ }^{[14,27]}$ On the other hand, Maggiore et al. in 2003 indicated that some of their participants experienced hypotension and bradycardia after suctioning which was explained by the fact that suctioning stimulates the cough reflex, increases intra-thoracic pressure, and decreases cardiac output and blood pressure. In addition, earlier studies, ${ }^{[22,28]}$ noted a decrease in oxygen saturations immediately after suctioning, however as noted in our results a decrease in $\mathrm{SaO}_{2}$ was not found between groups at day 5 . The differences in results is related to the time of measuring the physiologic parameters. In this study physiologic measures were collected every 3 hours for 5 days and averaged while previous studies assessed physiologic measures immediately after suctioning. Therefore, while alterations in physiologic measures are expected after suctioning these alterations are not permanent and may not have a negative impact on patients. 
Table 5. Logistic regression model of independent variables as risk factors for the development of probable ventilator-associated pneumonia*

\begin{tabular}{llll}
\hline Variables & Odds Ratios & Confidence interval (95\%) & $\boldsymbol{p}$ \\
\hline Age & & & \\
$21-40$ & 0.23 & $0.11-1.12$ & .13 \\
$41-60$ & 1.11 & $0.96-3.12$ & .09 \\
$61-80$ & 1.96 & $1.21-2.14$ & .04 \\
Suctioning with NS & 1.23 & $0.95-1.34$ & .06 \\
Antibiotic use & 0.44 & $0.07-0.767$ & .02 \\
WBC > 12,000 & 2.48 & $1.76-6.35$ & .05 \\
Amount of sputum & & & \\
Small & 3.20 & $0.68-6.16$ & .12 \\
Medium & 4.42 & $0.32-3.03$ & .32 \\
Large & 2.26 & $0.56-4.44$ & .29 \\
\hline
\end{tabular}

*Hosmer and Leme show Test showed an acceptable of model fit chi-square $(8)=22.24, p=.26$.

Table 6. Isolated organisms in 37 participants with 9 having more than one organism isolated

\begin{tabular}{|c|c|c|c|c|c|c|}
\hline \multirow{2}{*}{ Type of organism isolated } & \multicolumn{2}{|c|}{ Group $1(\mathrm{~N}=15)$} & \multicolumn{2}{|c|}{ Group $2(N=28)$} & \multicolumn{2}{|c|}{ Total $(\mathrm{N}=43)$} \\
\hline & Number & $\%$ & Number & $\%$ & Number & $\%$ \\
\hline Candida & 6 & 40 & 7 & 25.0 & 13 & 30.2 \\
\hline Escherichia coli & 3 & 20 & 6 & 21.4 & 9 & 20.9 \\
\hline Pseudomonas aeruginosa & 2 & 13.4 & 6 & 21.4 & 8 & 18.6 \\
\hline Klebsiella & 2 & 13.4 & 4 & 14.3 & 6 & 14.0 \\
\hline Enterobacter Species & 1 & 6.6 & 3 & 10.7 & 4 & 9.3 \\
\hline Acinetobacter & 1 & 6.6 & 1 & 3.6 & 2 & 4.7 \\
\hline Staphylococcus aureus & 0 & 0 & 1 & 3.6 & 1 & 2.3 \\
\hline Total & 15 & 100 & 28 & 100 & 43 & 100 \\
\hline
\end{tabular}

There were significantly more rates of VAC in patients who had NS installed. In terms of PVAP rates although the difference was not statistically significant, there were more than twice as many patients who developed PVAP in the group that had NS installed which is significant clinical finding. The lack of significant differences may be due to the small sample size. The proposed mechanism to this effect is that the instillation of normal saline prior to suctioning may dislodge bacteria from the biofilm inside the ETT that proceed to the lungs leading to infection. ${ }^{[29]}$ An opposing view is presented by Caruso et al. in 2009, who argued that NS instillation stimulates coughing decreasing the biofilm layer in the ETT tube which acts as a reservoir for bacteria.

In addition, inserting NS had been postulated to decrease the incidence of atelectasis due to secretion plugging. ${ }^{[11,15]}$ The differences in results could also be due to the different methods used to diagnose VAP. Earlier studies used criteria that are slightly different than the new 2015 CDC criteria. In addition, there may be variations in the settings where the studies were conducted. The latter 2 studies were conducted in the Western world where the type of organisms may differ and the sterile techniques followed by nurses may be more stringent. It is also worth noting, that in two studies. ${ }^{[11,15]}$ Lower VAP rates were reported in the group that had NS installed, however they assessed both early and late onset VAP whereas, in this study only early-onset PVAP was assessed (the first 4-5 days after MV). When looking at early onset VAP in the study done by Caruso et al. in 2009, the difference between groups was not significant $(p=.98)$ which is in accordance with our results. Based on the differences in study results further studies are recommend with larger sample sizes to decipher the mechanisms that can result in an increase or decrease in bacterial infections.

The $17.5 \%$ incidence of PVAP in this study is comparable to previous studies. For example, a study done by Muscedere, Martin \& Heyland in 2008 made up of 1,014 patients receiving MV and admitted to 16 ICUs in Canada quoted a VAP incidence rate of $15.5 \%$, while another study done by Kanj et al. in 2012 included ICUs in developing countries reported rates between $8.8 \%$ to $47 \% .^{[30,31]}$ Weighing our current study results against data from other countries in the Middle East, the incidence of VAP in Jordan is $23.9 \%, 21 \%$ 
in Palestine, $16.8 \%$ in Saudi Arabia and 16\% in Iran. ${ }^{[32-35]}$ The variations in rates are probably related to the various methods used in diagnosing and reporting VAP.

The factors associated with both VAC and PVAP were almost identical except for NS installation which was noted to be significant for VAC only. Older patents were more likely to develop VAC and PVAP which is in accordance with previous studies. ${ }^{[11,18]}$ The ability to resist infections decreases by age, where the ability to acquire infections increases. Females were less likely to develop PVAP but that difference did not reach significance. A WBC $>12,000$ was significantly associated with the development of both VAC and PVAP which is an expected finding supported by several studies done by Dudeck, Weiner \& Allen-Bridson in 2012 and Bouadma et al. in 2015. ${ }^{[36]}$ The amount of sputum was associated with development of VAC and PVAP, which was found to be associated with PVAP in a previous study. ${ }^{[37]}$ Antibiotic use was associated with VAC and PVAP in the current study, 27 (33.7\%) patients at baseline were on antibiotics and $70 \%$ were on antibiotics at day 5. Of the patients on antibiotics at day 5 only 3 developed PVAP while 11 patients who were not on antibiotics developed PVAP. The appropriate use of antimicrobial agents is striking a balance between maximizing clinical outcomes and minimizing resistant organisms. Among the initiatives are antimicrobial agent control programs (concerned with how to choose the antibiotic), prompt use of adequate empirical (broad-spectrum) therapy, use of combination therapy when needed, de-escalation of therapy whenever possible, shorter duration of therapy, and, perhaps, cycling of antimicrobials. ${ }^{[38]}$ The method of suctioning did was significant for VAC but did not reach significance for PVAP which may be explained by the small sample size resulting in type 2 error.

Thirty four (44\%) participants had positive cultures which is in line with previous reports done by Kalanuria et al. in 2015 and Jones in 2010 that indicate that bacteriologic confirmation of clinically suspected VAP ranges between $22 \%$ and 55\%. Patients are often on antimicrobial therapy at the time that endotracheal cultures were taken which affects the sensitivity of cultures. ${ }^{[37,39]}$ When comparing the distribution of organisms isolated in patients with early-onset PVAP in this study compared to other studies in Lebanon we noted similar organisms with some differences. The most common organisms isolated in this study were Candida followed by E-coloi and Pseudomonas whereas the study by Kanj et al. in 2012, noted that the most common device associated microorganism was E. coli (32.7\%), followed by Candida (9.1\%), and Klebsiella spp. (7.3\%). In comparison to studies in the West, a large study in Germany found that the most common organisms in early onset VAP were S. aureus, followed by P. aeruginosa, K. pneumoniae, and E. coli. ${ }^{[10]}$ A surveillance program which collected microbiological data from 1997 to 2008 in hospitalized patients with pneumonia from North America, Europe, and Latin America, found that the top six pathogens isolated from patients with nosocomial pneumonia were S. aureus (28.0\%), P. aeruginosa (21.8\%), Klebsiella species (9.8\%), E. coli (6.9\%), Acinetobacter species (6.8\%), and Enterobacter species (6.3\%). ${ }^{[38,39]}$ The variations in pathogens isolated in different studies and countries may reflect the timing of diagnoses as well as changing trends of organisms over time. Gram-negative pathogens have increased over time as noted in most studies including ours whereby Pseudomonas aeruginosa was the third most common organism isolated.

\section{LiMiTATIONS}

Despite the strengths of this study which include vigorous monitoring of physiologic measures over 5 days, there are several limitations worth mentioning. First the study was conducted in a single center single center using a qausiexperimental design which limits generalizations. Second the study, by the nature of the equipment used, it was unblinded at the bedside albeit, the radiologists, physicians and the laboratory staff were unaware of the treatment groups. Third, the intervention group at baseline had significantly more excessive secretions which may have had an effect on the rates of VAC and PVAP. Lastly, the sample size was not large enough to detect a significant difference in the rates of PVAP between groups even though a trend for an increase in PVAP was noted in the group that had NS Installed.

\section{CONCLUSION AND RECOMMENDATIONS}

Although several earlier studies have tested the benefits and drawbacks of NS installation before suctioning the findings remain inconsistent. Based on the findings of the current study, it is recommended that routine instillation of NS into the tracheal tube during the suction procedure should not be performed routinely on all patients albeit, further studies are warranted. In addition, in-service training programs on the updated CDC guidelines should be conducted in order to assist professionals in the accurate diagnosis of VAP. Since patients on MV are at high risk of acquiring nosocomial infections, which increases mortality and morbidity, ICU stay, and costs, it is also recommended that aseptic techniques be used with a closed suction system. Finally due to the paucity of RCTs on the best methods for suctioning there is room for additional well controlled studies to make evidence based recommendations for clinical practice.

\section{CONFlicts OF INTEREST Disclosure}

The authors declare that there is no conflict of interest. 


\section{REFERENCES}

[1] Chastre J, Fagon JY. Ventilator-associated pneumonia. Am J Respir Crit Care Med. 2002; 165: 867-903. PMid:11934711 http://dx.d oi.org/10.1164/ajrccm.165.7.2105078

[2] Leach R. Acute and Critical Care Medicine at a Glance, 2nd ed. UK: Wiley-Blackwell. 2009.

[3] Guillamet CV, Kollef MH. Update on ventilator-associated pneumonia. Curr Opin Crit Care. 2015; 21(5): 430-8. PMid:26348421 http://dx.doi.org/10.1097/MCC.0000000000000231

[4] Safdar N, Dezfulian C, Collard HR, et al. Clinical and economic consequences of ventilatorassociated pneumonia: a systematic review. Crit Care Med. 2005; 33: 2184-93. http://dx.doi .org/10.10 97/01. CCM.0000181731.53912.D9

[5] CDC Surveillance for Ventilator-associated Events. 2015.

[6] Dudeck MA, Weiner LM, Allen-Bridson K. National Healthcare Safety Network (NHSN) Report, Data Summary for 2012, "Device associated Module". Am J of Infection Control. 2013; 41: 114866. PMid:24274911 http://dx.doi.org/10.1016/j.ajic. 20 13.09 .002

[7] Khan R, Al-Dorzi HM, Al-Attas K, et al. The impact of implementing multifaceted interventions on the prevention of ventilatorassociated pneumonia. Am J Infect Control. 2016 Mar 1; 44(3): 320-6. PMid:26940595 http://dx.doi.org/10.1016/j.ajic. 2015.09 .025

[8] Zilberberg MD, Shorr AF, Kollef MH. Implementing quality improvements in the intensive care unit: ventilator bundle as an example. Crit Care Med. 2009; 37: 305-309. PMid:19050626 http: //dx.doi.org/10.1097/CCM.0b013e3181926623

[9] Rewa O, Muscedere J. Ventilator-associated pneumonia: update on etiology, prevention, and management. Curr Infect Dis Rep. 2011; 13(3): 287-95. PMid:21399891 http://dx.doi.org/10.1007/s 11908-011-0177-9

[10] Ayhan H, Tastan S, Iyigun E, et al. Normal saline instillation before 2nd otracheal suctioning: "What does the evidence say? What do the nurses think?": Multimethod study. Journal of Critical Care. 2015; 30(4):762-7. PMid:25841280 http://dx. doi .org/10.10 $16 / \mathrm{j} \cdot \mathrm{jcrc} .2015 .02 .019$

[11] Caruso P, Denari S, Ruiz SA, et al. Saline instillation before tracheal suctioning decreases the incidence of ventilator-associated pneumonia. Crit Care Med. 2009; 37(1): 32-8. PMid:19050607 http://dx.doi.org/10.1097/CCM.0b013e3181930026

[12] Sole ML, Byers JF, Ludy JE, et al. A multisite survey of suctioning techniques and airway management practices. Am J Crit Care. 2003; 12: 220-230. PMid:12751396

[13] Nair GB, Niederman MS. Ventilator-associated pneumonia: present understanding and ongoing debates. Intensive Care Med. 2015; 41(1): 34-48. PMid:25427866 http://dx.doi.org/10.1007/s 00134-014-3564-5

[14] Zahran EM, Abd El-Razik AA. Tracheal suctioning with versus without saline instillation. AMJ Sci. 2011; 7(8): 23-32.

[15] Reeve JC. Instillation of normal saline before suctioning reduces the incidence of pneumonia in intubated and ventilated adults. Aust J Physiother. 2009; 55(2): 136. http://dx.doi.org/10.1016/S00 04-9514 (09) 70044-3

[16] American Association for Respiratory Care. (AARC) Clinical Practice Guidelines. Endotracheal suctioning of mechanically ventilated patients with artificial airways. Respir Care. 2010; 55(6): 758-64. PMid:20507660

[17] Celik SA, Kanan N. A current conflict: use of isotonic sodium chloride solution on endotracheal suctioning in critically ill patients. Dimens Crit Care Nurs. 2006; 25(1): 11-4. PMid:16501363 http://dx.doi.org/10.1097/00003465-200601000-00003
[18] Halm MA, Krisko-Hagel K. Instilling normal saline with suctioning: beneficial technique or potentially harmful sacred cow? Am J Crit Care. 2008; 17(5): 469-72. PMid:18776003

[19] O'Grady NP, Murray PR, Ames N. Preventing ventilator-associated pneumonia: does the evidence support the practice? JAMA. 2012; 307(23): 2534-9. http://dx.doi.org/10.1001/jama.2012.6 445

[20] Bakhtiari S, Yazdannik A, Abbasi S, et al. The effect of an upper respiratory care program on incidence of ventilator-associated pneumonia in mechanically ventilated patients hospitalized in intensive care units. Iran J Nurs Midwifery Res. 2015; 20(3): 354-8. PMid:26120336

[21] Gutiérrez JM, Millare PA, Al-Shenqiti YA, et al. Exposure to reprocessed single-use tracheal suction catheter and ventilator-associated pneumonia risk: A preliminary, single unit-based, matched casecontrol study. J Crit Care. 2016; 32: 145-51. PMid:26775186 http://dx.doi.org/10.1016/j.jcrc.2015.11.018

[22] Giakoumidakis K, Kostaki Z, Patelarou E, et al. Oxygen saturation and secretion weight after endotracheal suctioning. Br J Nurs. 2011; 20(21): 1344-51. PMid:22241423 http://dx.doi.org/10.1296 8/bjon.2011.20.21.1344

[23] O’Neal PV, Grap MJ, Munro CL, et al. Subglottic secretion volume and viscosity: effect of systemic volume and oral hydration. Dynamics. 2014; 25(1): 19-25. PMid:24716391

[24] Kiehlbauch J, Hannett G, Salfinger M, et al. Use of the national committee for clinical laboratory standards guidelines for disk diffusion susceptibility testing in Nnew York state laboratories. Clin Microbiol. 2000; 38(9): 3341-8.

[25] Iranmanesh S, Rafiei H. Normal saline instillation with suctioning and its effect on oxygen saturation, heart rate, and cardiac rhythm. Int J Nurs Educ. 2011; 3(1): 42-4.

[26] Conti M, Merlani P, Ricou B. Prognosis and quality of life of elderly patients after intensive care. Swiss Med Wkly. 2012. PMid:22965434 http://dx.doi.org/10.4414/smw.2012.13671

[27] Akgul S, Akyolcu N. Effects of normal saline on endotracheal suctioning. Journal of Clinical Nursing. 2002: 11(6): 826-30. PMid:12427189 http://dx.doi.org/10.1046/j.1365-2702. 2002.00655.x

[28] Maggiore SM, Lellouche F, Pigeot J, et al. Prevention of endotracheal suctioning-induced alveolar de recruitment in acute lung injury. Am J Respir Crit Care Med. 2003; 167(9): 1215-24. PMid:12615633 http://dx.doi.org/10.1164/rccm.200203-1950C

[29] Hagler DA, Traver GA. Endotracheal saline and suction catheters: sources of lower airway contamination. Am J Crit Care 1994; 3 : 444-7. PMid:7834003

[30] Muscedere JG, Martin CM, Heyland DK. The impact of ventilatorassociated pneumonia on the Canadian health care system. J Crit Care. 2008; 23: 5-10. PMid:18359415

[31] Kanj S, Kanafani Z, Sidani N, et al. International nosocomial infection control consortium findings of device-associated infections rate in an intensive care unit of a Lebanese university hospital. J Glob Infect Dis. 2012: 4(1): 15-21. PMid:22529622 http: //dx.doi.org/10.4103/0974-777X.93755

[32] Khuri-Bulos NA, Shennak M, Agabi S. Nosocomial infections in the intensive care units at a university hospital in a developing country: comparison with National Nosocomial Infections Surveillance intensive care unit rates. Am J Infect Control. 1999; 27: 547-52. http://dx . doi .org/10.1016/S0196-6553(99)70035-0

[33] Memish ZA, Cunningham G, Oni GA, et al. The incidence and risk factors of ventilator associated pneumonia in a Riyadh hospital. Infect Control Hosp Epidemiol. 2000; 21(4): 271-3. PMid:10782591 http://dx.doi.org/10.1086/501758 
[34] Speksnijder H, Trogrlić Z, Lima A, et al. Endotracheal suctioning with non-sterile gloves and only when necessary! Intensive Care Med. 2015; 41(8): 1500-1. PMid:26077085 http://dx.doi.org /10.1007/s00134-015-3895-x

[35] Ruzieh M, Al-Ardeh M, Nazzal Z. Incidence and risk factors of ventilator associated pneumonia (VAP) in Palestine Hospitals. Sci Rep. 2013; 2: 625. http://dx.doi.org/10.4172/scientifi creports. 625

[36] Bouadma L, Sonneville R, Garrouste-Orgeas M, et al. VentilatorAssociated Events: Prevalence, Outcome, and Relationship With Ventilator- Associated Pneumonia. Crit Care Med. 2015; 43(9): 1798806. PMid:25978340 http://dx.doi.org/10.1097/CCM. 00000 00000001091

[37] Kalanuria AA, Fellerman D, Nyquist P, et al. Variability in Diagnosis and Treatment of Ventilator-Associated Pneumonia in Neurocritical
Care Patients. Neurocrit Care. 2015; 23(1): 44-53. PMid:25634643 http://dx.doi.org/10.1007/s12028-015-0109-x

[38] Paterson DL. The role of antimicrobial management programs in optimizing antibiotic prescribing within hospitals. Clin Infect Dis 2006; 42(2): 90-5. PMid:16355322 http://dx.doi.org/10.10 $86 / 499407$

[39] Jones RN. Microbial etiologies of hospital-acquired bacterial pneumonia and ventilatorassociated bacterial pneumonia. Clin Infect Dis 2010; 50: S81-S87. PMid:20597676 http://dx.doi .org/10.10 $86 / 653053$

[40] Gastmeier P, Sohr D, Geffers C, et al. Early and late-onset pneumonia: is this still a useful classification? Antimicrob Agents Chemother 2009; 53(7): 2714-18. PMid:19364852 http://dx.doi.org/10. 1128/AAC.01070-08 